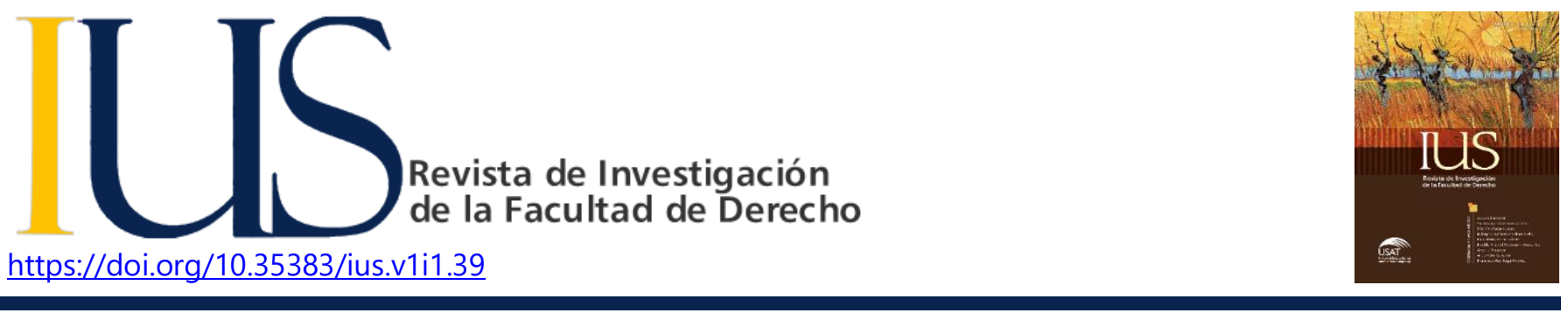

\title{
LA NECESIDAD DE FORTALECER LAS ESTRATEGIAS PARA LA PREVENCIÓN DE LAVADO DE ACTIVOS. REFLEXIONES DESDE LA PERSPECTIVA DEL DERECHO FINANCIERO Luis Henry Heras Zárate ${ }^{1}$
}

\section{INFORMACIÓN DEL ARTÍCULO Historia del artículo: \\ Recibido el 1 de octubre de 2018 \\ Aceptado el 19 de marzo de 2019}

\section{Palabras claves:}

Derecho financiero

Lavado de activos

Bancos

\section{RESUMEN}

Planteamos que en cumplimiento de los artículos $8^{\circ}$ y $44^{\circ}$ de Nuestra Constitución Política del Perú, constituye un deber del Estado peruano luchar contra el narcotráfico y sus delitos confluyentes o colaterales como es el lavado de activos. Para ello es necesario una revisión y modificación a nuestro ordenamiento jurídico en relación al fortalecimiento de las estrategias para no solo enfrentar, sino también prevenir el lavado de activos en el Perú. Nuestra investigación se desarrolla, a partir de las instituciones financieras, bancos, bolsas de valores, casas de cambio y las empresas que brindan diferentes clases de bienes y servicios, y en forma particular las compañías que operan en el plano transnacional y que están acechadas o involucradas con el lavado de activos, pues los lavadores buscan la forma de burlar las fronteras de los Estados en donde las actividades ilícitas se desarrollan, y consideramos que el lavado de activos se ha convertido en un problema de estándar global que debilita la economía del mundo, es por eso que esta propuesta de investigación apunta a verificar y fortalecer aquellas estrategias legales que combaten el lavado de activos desde el Derecho Financiero .

The need to strengthen the strategies for the prevention of money laundering. Reflections from the perspective of financial law

\section{ABSTRACT}

Keywords:

Financial Law

Money laundering

Banks
We propose that in compliance with Articles $8^{\circ}$ and $44^{\circ}$ of our Political Constitution of Peru, it is a duty of the Peruvian State to fight against drug trafficking and its confluent or collateral crimes such as money laundering. This requires a revision and modification of our legal

\footnotetext{
${ }^{1}$ Máster en Derecho con mención en Derecho de la Empresa en la Universidad de Piura. Abogado por la Universidad Privada Antenor Orrego. Con estudios de especialización en Banca y Finanzas por el Instituto de Formación Bancaria \& Asociación de Bancos del Perú, IFB - ASBANC. Área de Derecho de la Empresa, Facultad de Derecho de la Universidad Católica Santo Toribio de Mogrovejo. Email: lheras@usat.edu.pe
} 
system in relation to strengthening strategies to not only face, but also prevent money laundering in Peru.

It is in this context that our research is developed, from financial institutions, banks, stock exchanges, exchange houses and companies that provide different kinds of goods and services, and in (sin in) particular companies operating at the transnational level, and that they are(that are) harassed or involved with money laundering, as the launderers seek to circumvent the borders of the states where illicit activities take place, and we believe that money laundering has become a global standard problem that weakens the world's economy, that is why this research proposal aims to verify and strengthen those legal strategies that combat money laundering from the Financial Law.

\section{INTRODUCCIÓN}

Desde hace varios años se viene librando una de las más grandes guerras económicas en el interior del sector financiero. El Estado se enfrenta a uno de sus mayores, y más antiguos enemigos, el lavado de activos. Hoy, en el contexto del evolucionado siglo XXI esta problemática ha vuelto a cobrar vigencia, y cada vez es más frecuente encontrar en los titulares de noticias aperturas de investigaciones por este tipo de hechos.

Como es bien conocido, lavar activos significa ocultar el origen de bienes o caudales obtenidos de actividades ilícitas, es decir, de delitos previos, como el narcotráfico, la minería ilegal o la corrupción. En ese contexto, puede resultar común que el "lavador" ignore los detalles de los crímenes previos, como parte de una estrategia diseñada para proteger a quienes propiciaron el "dinero sucio". Esto hace que para las autoridades resulte difícil identificar claramente las circunstancias del delito del que proviene el dinero que se quiere lavar (el Ilamado "delito fuente") y a sus responsables.

De acuerdo a la definición proporcionada por la Superintendencia de Banca y Seguros (SBS), el lavado de activos es el conjunto de operaciones realizadas por una o más personas naturales 0 jurídicas, tendientes a ocultar o disfrazar el origen ilícito de bienes o recursos que provienen de actividades delictivas (SBS, 2017). Por lo general, este delito se desarrolla mediante la realización de varias operaciones, encaminadas a encubrir cualquier rastro del origen ilícito de los recursos (Berman, 2006; Sánchez, 2002). Es decir, el dinero ilegal busca refugio y legitimación en los servicios o negocios que ofrecen y realizan las entidades financieras. En la mayoría de casos se usa la colocación diversificada de dinero entregados en distintos ámbitos, de tal manera que el dinero, adoptando una forma ilícita, se convierta en dinero formal, aun cuando la actividad que la ha generado no lo sea.

Los flujos monetarios que se manejan en este tipo de operaciones son increíblemente elevados. El lavado de activos representa entre el $2 \%$ y el $5 \%$ del Producto Bruto Interno Mundial (Sánchez, 2002, p. 6). Los cálculos realizados por el Fondo Monetario Internacional y la Organización de las Naciones Unidas, indican que al año se lavan activos de unos US\$1.5 a 2.0 billones. Esto equivale a la tercera parte de las divisas de todos los Bancos Centrales. Según estimado del Banco Interamericano de Desarrollo, en América del Sur las operaciones por lavado de activos fluctúa entre el $2.5 \%$ a $6.3 \%$ del Producto Bruto Interno anual de la región (SBS, 2011).

Desde el 26 de junio del 2002, fecha en la que el Perú promulgó la ley contra el Lavado de Activos (Ley $\mathrm{N}^{\circ}$ 27765), las autoridades del sector financiero nacional han tomado mayor 
responsabilidad para hacer frente a este escenario, y lograr estabilizar el desenvolvimiento de nuestros flujos de capitales.

Aparentemente el problema del lavado es un tema que compete desarrollarlo desde la óptica del Derecho Penal; sin embargo, la búsqueda de soluciones para los conflictos socio-económicos que estos hechos generan es competencia de todas las ramas jurídicas, especialmente del Derecho del Sistema Financiero. Es el Derecho del Mercado Financiero quien tiene mayor responsabilidad para hacer frente a este tipo de sucesos, dado que es en este escenario, donde el dinero obtenido ilícitamente, puede recobrar la licitud de sus movimientos. Así también porque los Bancos, Cajas y demás entidades financieras juegan un rol importante en la política económica del país, toda vez que se han perfilado como entidades cuya finalidad es comercializar dinero. De ahí que resultará de utilidad estratégica localizar la intervención del dinero de origen ilícito, cuando menos en el momento se su colocación en las agencias bancarias.

En tal sentido, es imprescindible contar con la colaboración de las propias empresas del Sistema Financiero, así como de sus empleados y funcionarios. En los últimos años se han venido planteando una serie de iniciativas internacionales con la finalidad de fortalecer el sistema bancario, a los fines de que pueda hacer frente de una forma eficaz ante el crecimiento de actividades criminales $y$ sus relaciones con el mundo financiero. Se ha señalado que el sistema bancario puede desarrollar un rol preventivo extremadamente eficaz y, al mismo tiempo, generar una cooperación de los bancos para prevenir estas actividades (Prado, 2007, p. 42).

El desarrollo del presente artículo tiene por finalidad plantear la realidad de los procesos de lavado de activos y analizarlo, no sólo desde la perspectiva de la dogmática penal, sino desde la óptica del Derecho del Sistema Financiero, quien ha asumido el reto de hacer frente a este gran enemigo económico.

\section{MARCO NORMATIVO:}

- La Convención de las Naciones Unidas contra el Tráfico Ilícito de Estupefacientes y Sustancias Psicotrópicas (1 988)

- La Declaración de Principios de Basilea sobre Prevención de la Utilización del Sistema Bancario para Blanquear Fondos de Origen Criminal, del Comité sobre Regulación y Supervisión Bancaria del Grupo de los 10, (1988)

- El Informe y Recomendaciones del Grupo de Acción Financiera sobre el Blanqueo de Dinero GAFI (1990)

- Ley $N^{\circ}$ 26702, Ley General del Sistema Financiero y del Sistema de Seguros y Orgánica de la Superintendencia de Banca, Seguros y Administradoras de Fondos de Pensiones.

- Ley $N^{\circ}$ 27765, Ley Penal contra el Lavado de Activos.

- Ley N² 29038, Ley que incorpora la Unidad de Inteligencia Financiera del Perú (UIF-Perú) a la Superintendencia de Banca y Seguros y Administradoras Privadas de Fondos de Pensiones.

- Convención de las Naciones Unidas contra la Corrupción, Nueva York, 2004.

- Normas para la Prevención del Lavado de Activos y Financiamiento del Terrorismo, de aplicación general a los sujetos obligados a informar que carecen de organismos supervisores. R. SBS N 486-2008.

- Decreto Supremos $N^{\circ}$ 057-2011-PCM. Aprobado el 30 de junio del 2011 y publicado el 01 de Julio del 2011 en el Diario Oficial "El Peruano".

\section{EL SISTEMA FINANCIERO}

El Sistema Financiero peruano está compuesto por dos subgrupos; por aquellos que son participantes directos del Sistema Financiero, a través del Mercado de Valores o Capitales; y por aquellos que pertenecen a la esfera de la intermediación indirecta. Dentro del primer subgrupo se encuentran las Sociedades Agentes de Bolsa, los emisores de valores, los inversionistas institucionales, las Bolsas, los Fondos Mutuos y los Fondos de Inversión entre otros. Dentro del 
segundo grupo se encuentran las empresas que realizan operaciones bancarias, las empresas de Seguros y Reaseguros y las empresas que administran los fondos privados de pensiones (Figueroa, 2010).

Fundamentalmente, las empresas financieras son reguladas y supervisadas por dos agencias gubernamentales: La Superintendencia Nacional del Mercado de Valores, la cual tiene a su cargo las empresas que realizan actividades de intermediación directa; y la Superintendencia de Banca, Seguros y AFP del Perú (SBS) que está encargada de aquellas empresas que realizan intermediación indirecta y las que prestan servicios complementarios y conexos.

Por otro lado, en este escenario también actúa el Banco Central de la Reserva del Perú (BCRP) quien tiene facultades para regular los instrumentos de política monetaria tales como el encaje y el sobre encaje en moneda nacional y extranjera, las operaciones de mercado abierto de instrumentos y moneda extranjera, así como los créditos con fines de regulación monetaria; pero con independencia propia.

En el proceso de lavado de activos, cualquier estructura del Sistema Financiero ha constituido siempre una vía natural de tránsito de los bienes obtenidos ilícitamente (Prado, 2007, p. 44). La mala utilización y el abuso de este sistema es un elemento identificativo del blanqueo de capitales. Es el Mercado Financiero y sus agentes quienes resultan siendo los accesos de inicio o conclusión, en una $u$ otra forma, del circuito delictivo que recorren las organizaciones criminales dedicadas a brindar estos "servicios".

Ahora, aun cuando la esencia del blanqueo de dinero no ha cambiado a través de los siglos, el contexto en el que este ocurre ha evolucionado considerablemente. Son tres las operaciones esenciales contra el blanqueo de dinero: el descubrimiento y localización del producto del delito y de los activos dimanantes de ese producto, su congelación y su decomiso y confiscación (Prado, 2007, p. 44); y es en este ciclo de operaciones donde interviene el Derecho Financiero.

\section{REGULACIÓN DEL LAVADO DE ACTIVOS EN EL PERÚ}

De acuerdo a la Ley $\mathrm{N}^{\circ} 27765$ publicada el 26 de julio de 2002, y en concordancia con las modificaciones introducidas por el Artículo Único del Decreto Legislativo $N^{\circ} 986$ del 22 de julio de 2007, existen dos formas de lavar activos:

"Artículo 1.- Actos de Conversión y Transferencia. - El que convierte o transfiere dinero, bienes, efectos o ganancias cuyo origen ilícito conoce o puede presumir, y dificulta la identificación de su origen, su incautación o decomiso; será reprimido con pena privativa de la libertad no menor de ocho ni mayor de quince años y con ciento veinte a trescientos cincuenta días multa."

"Artículo 2.- Actos de Ocultamiento y Tenencia.El que adquiere, utiliza, guarda, custodia, recibe, oculta, administra o transporta dentro del territorio de la República o introduce o retira del mismo o mantiene en su poder dinero, bienes, efectos o ganancias, cuyo origen ilícito conoce o puede presumir, y dificulta la identificación de su origen, su incautación o decomiso, será reprimido con pena privativa de la libertad no menor de ocho ni mayor de quince años y con ciento veinte a trescientos cincuenta días multa."

De forma complementaria el inciso segundo del artículo $6^{\circ}$ del Decreto legislativo $N^{\circ} 986$, dispone: "El conocimiento del origen ilícito que debe conocer o presumir el agente de los delitos que contempla la presente ley, corresponde a conductas punibles en la legislación penal como el tráfico ilícito de drogas; terrorismo; delitos contra la administración pública; secuestro; extorsión; proxenetismo; trata de personas; tráfico ilícito de migrantes; defraudación tributaria; contra el patrimonio en su modalidad agravada; delitos aduaneros, $u$ otros similares que generen ganancias ilegales, con excepción de los actos contemplados en el artículo 194 del Código Penal." En complemento a ello, recientemente el I Pleno Jurisdiccional Casatorio de las Salas Permanente y Transitorias de la Corte Suprema mediante Sentencia Casatoria $N^{\circ} 1-2017 / \mathrm{CIJ}^{\circ} 433$ publicada 
el 25 de octubre del 2017 ha fijado algunos lineamientos para configurar este delito:

a) El delito de lavado de activos es un delito autónomo, tanto en su configuración material como para los efectos de su persecución procesal.

b) El artículo 10 de la Ley de lucha eficaz contra el lavado de activos, Decreto Legislativo $\mathrm{N}^{\circ}$ 1106 , modificado por el Decreto Legislativo $\mathrm{N}^{\circ}$ 1249 , es una disposición meramente declarativa y de reconocimiento. No es un tipo penal o un tipo complementario.

c) El "origen delictivo", mencionado por el citado artículo 10, es un componente normativo. El origen del activo debe corresponder necesariamente a actividades criminales que tengan la capacidad de generar ganancias ilícitas y requerir el auxilio de operaciones de lavado de activos. La ley no alude a un elemento de gravedad de la actividad criminal precedente; no optó por el enfoque del "umbral".

d) La noción "actividades criminales" no puede entenderse como la existencia concreta y específica de un precedente delictivo de determinada naturaleza, cronología, intervención o roles de agentes delictivos individualizados y objeto. Basta la acreditación de la actividad criminal de modo genérico.

e) El estándar o grado de convicción no es el mismo durante el desarrollo de la actividad procesal o del procedimiento penal: la ley fija esos niveles de conocimiento. Varía, progresivamente, en intensidad.

f) Para iniciar diligencias preliminares solo se exige elementos de convicción que sostengan una "sospecha inicial simple", para formalizar la investigación preparatoria se necesita "sospecha reveladora", para acusar y dictar auto de enjuiciamiento se precisa "sospecha suficiente", y para proferir auto de prisión preventiva se demanda "sospecha grave" (la sospecha más fuerte en momentos anteriores al pronunciamiento de una sentencia). La sentencia condenatoria requiere elementos de prueba más allá de toda duda razonable.

\section{PROCESO DE LAVADO DE ACTIVOS}

El lavado de activos es un delito sofisticado que requiere la creación de planes estratégicos para su implementación, el diseño de programas de acción y el desarrollo de una producción de bienes y servicios para legalizar el dinero obtenido ilícitamente.

La distinción de las etapas del proceso de lavado de activos puede variar. Algunos autores consideran que pueden existir entre tres o hasta cuatro etapas. Veamos:

- Obtención de dinero en efectivo o medios de pago, como consecuencia de actividades ilícitas (venta de productos o prestación servicios ilícitos).

Colocación de los fondos. Esta etapa se materializa en la incorporación del producto ilícito en el Sistema Financiero nacional o internacional, a través de los diferentes mecanismos que tiene este sistema para operar. El dinero puede ser transformado en instrumentos de pago tales como cheques de gerencia, cheques de viajero $u$ órdenes de pago que tienen como ventaja su fácil aceptación y la carencia de un titular específico, el cual facilita el tránsito y el encubrimiento del lavado (Prado, 2007, p. 47). Es decir, el dinero ilícito ingresa a los fondos a la economía legal a través de los circuitos financieros institucionalizados. Esta es la etapa más difícil para los lavadores, quienes deben desafiar las propuestas metodológicas de prevención existentes (Sánchez, 2002, p. 26).

- Decantación o intercalación de los fondos. Estratificación, diversificación o transformación: Esta etapa comienza cuando el dinero ha sido introducido en una entidad financiera o no financiera. En este marco, los clientes lavadores estructuran operaciones, para ocultar, invertir, transformar, asegurar o dar en custodia bienes provenientes del delito, con la finalidad de mezclar el dinero con aquel de origen legal. De esta manera podrán disimular su origen ilícito y alejarlos de su verdadera fuente. Todo ello con el fin de transferir el dinero de una cuenta a otra, o de una sociedad 
a otra en distintas entidades financieras y hasta en distintos países (Sánchez, 2002, p. 26).

En esta etapa el despliegue de las habilidades para operar en el Sistema Financiero se pone de relieve. La operación más común es la transferencia de fondos, desde o hacia cuentas en el exterior, o se abren nuevas cuentas en el país de origen; todo a fin de recibir los pagos de créditos, los cuales se ejecutan, casi siempre, a través de nuevos cheques emitidos por terceros (Prado, 2007).

- Integración de los fondos. Finalmente llega la etapa de integración, inversión o goce de los capitales ilícitos. Es decir, el dinero ilícito regresa al Sistema Financiero o no financiero, disfrazado de dinero legítimo. Lo ideal es que en esta etapa se logre haber perdido el rastro de la procedencia del dinero, dado que en la etapa anterior debieron darse sucesivas transformaciones. Entonces, se plantea la convergencia de ambos ámbitos de la economía, el legal y el ilegal, y se logra un proceso complementario. La totalidad de dichas prácticas ilegales y criminales utilizan los mismos intermediarios y a las mismas técnicas: paraísos fiscales, sociedades fiduciarias, mercados financieros, etc. (Prado, 2007).

Veamos un ejemplo. El lavador podría depositar el efectivo en una institución financiera regulada, por ejemplo, un banco o una empresa de valores. $O$ también podría adquirir bienes activos de elevado valor como, por ejemplo, automóviles, propiedades inmuebles o joyas. Así también el lavador podrá comprar o vender valores, metales preciosos $u$ otros activos costosos, realizando el máximo de operaciones para desviar la verdadera fuente de los activos. Por último el lavador puede establecer una actividad intensiva en efectivo, por ejemplo, un restaurante o una tienda de alquiler de videos, donde los fondos ilegales puedan ser inyectados y reaparecer como ganancias ficticias o re-pago de préstamos (SBS, 2017).

\section{EL LAVADO DE ACTIVOS DESDE LA PERSPECTIVA DEL DERECHO DEL SISTEMA FINANCIERO}

\subsection{Finalidad de Lavar Activos}

Entre los instrumentos más utilizado para disimular el origen del dinero figuran las letras bancarias, fideicomisos, auto préstamos y swaps, y como consecuencia del desarrollo de técnicas más modernas de lavado de dinero, existe ahora una demanda de profesionales tales como notarios, abogados y contadores capaces de elaborar estructuras complejas para aprovechar las falencias en materia de regulación y control, y las diferencias entre los ordenamientos jurídicos de diversos países que pueden ser aprovechadas para la comisión de un delito que, como el lavado de activos, es eminentemente transnacional (Bauché, 2002, p. 32).

Desde una perspectiva amplia los beneficios obtenidos por la realización de estas actividades pueden agruparse en dos sectores.

Por un lado, estas estrategias tienen una finalidad inmediata, la cual está orientada a utilizar y/o disfrutar los bienes obtenidos de las actividades ilícitas, sin el riesgo que sean detectadas. Para tales fines, los delincuentes, haciendo uso de los circuitos económicos, pretenden disfrutar de sus ganancias ilícitamente obtenidas. Sin embargo, en algunos casos las estrategias de incorporación no son del todo idóneas, por lo que se originan algunas pérdidas en términos económicos. A pesar de ello, esta situación es irrelevante, dado que a los lavadores no les interesa o les interesa muy poco dicha pérdida, toda vez que lo consideran como parte del mismo negocio.

Pero además, existe también un fin secundario, el cual consiste en alejar las ganancias ilícitas de cualquier relación con el delito, borrando cualquier rastro ilícito para evitar algún intento de seguimiento (Salazar, s,f,).

Ambos objetivos ponen de relieve que la intensión de los lavadores en la ejecución de este tipo de estrategias, y cuyos efectos no van más allá de la manipulación del Sistema Financiero.

\subsection{Trascendencia económica del Lavado de Activos}

El lavado de activos tiene un efecto corrosivo en la economía, el gobierno y el bienestar social de un 
país, así como el aumento de riesgo de la quiebra bancaria, se quita al gobierno el control de la política económica, se daña la reputación del país y se expone a la sociedad al tráfico de drogas, al contrabando y a otras actividades delictivas (Lester, 2001).

Para el sector privado los efectos son distintos. Por ejemplo se crean empresas "fachadas" cuyo fin último no es la producción eficiente, sino únicamente mezclar las ganancias de actividades ilícitas con fondos legítimos para ocultar sus ingresos mal habidos. Sin embargo, puede tratarse de compañías que, paralelamente a la actividad ilícita, se dediquen a fortalecer sus ventajas competitivas, a través de la implementación de insumos que puedan servir a la producción, o la oferta de productos por debajo del costo de transacción, o permitiéndose subvencionar artículos y servicios a niveles por debajo de los precios del mercado. Sin embargo esto no desconoce la existencia de compañías poco eficientes, y que en última instancia terminan perjudicando, no sólo la estabilidad del mercado sino también al consumidor (McDowell, 2001).

La movilidad de los capitales y mercancías, la desaparición de barreras aduaneras, la facilidad y rapidez de las comunicaciones y transferencias de todo tipo, así como la supresión de las normas sobre control de cambio, han facilitado el enorme desarrollo del blanqueo de capitales de origen criminal en los últimos años. De esta forma el blanqueo de activos se convierte en el instrumento básico a través del cual los enormes beneficios provenientes de la droga y el crimen organizado se canalizan, con moderna mentalidad empresarial, hacia los sectores económicos, que llegan incluso a controlar en algunos países (Paullier, 2011). Todo esto acarrea enormes perjuicios para la economía en general, introduciendo en la misma elementos que la distorsionan de forma importante, detraen recursos productivos, afectan a la libre competencia, producen movimientos especulativos, graves incertidumbres $y$ confusiones en los mercados; y en definitiva, pueden llevar a la propia desaparición del Sistema Financiero (Paullier, 2011).
Desde el punto de vista de la macro-economía, Miguel Cano (2001) establece algunos efectos que genera el lavado de activos:

\section{Debilitamiento de la integridad de los} mercados financieros y corrupción del Sistema Financiero. Una de las etapas del proceso de lavado de activos, y tal vez la principal, es la integración del dinero que proviene de fuente ilícita y el dinero circulante de origen legal. Por lo general, esta acción se realiza a través de operaciones del Sistema Financiero. El ingreso y circulación del dinero y demás activos obtenidos ilícitamente infectan la economía nacional y terminan corrompiendo sus estructuras financieras. Estas operaciones son uno de los mayores peligros para los países en vías de desarrollo, quienes al aceptar fondos, para sostener y beneficiar su economía, sin tener en cuenta su posible origen ilegal, alteran el desenvolvimiento normal de los flujos, permitiendo que el crimen organizado penetre en su sistema bancario y lo contamine. Estos grupos organizados pueden infiltrarse en las instituciones financieras, adquirir luego el control de éstas y posteriormente de sectores de la economía, todo lo cual puede llegar reflejado el soborno eventual a funcionario públicos para lograr sus objetivos. Cuando se produce este movimiento en el Sistema Financiero de un país, las constantes entradas y salidas de capitales pueden afectar significativamente variables tales como las tasas de interés y la tasa de cambio de moneda (Bauché, 2006, p. 34).

- Pérdida del control de la política económica. El límite de las facultades que adquieren las personas que lavan dinero inimaginable. Estos llegan a manejar un poder de tal magnitud que tienen la posibilidad, incluso, de desestabilizar, la economía de un país. Esto se debe al carácter transfronterizo de las operaciones, las cuales pueden 
orientarse a depositar dinero en el país A, para unos meses después retirarlo $y$ depositarlo en el país B (Bauché, 2006, p. 34). Los flujos monetarios que entran en juego son tales, que llegan generar una pérdida de la estabilidad económica.

- Distorsión económica e inestabilidad. La verdadera finalidad de las personas que se dedican a lavar dinero no es generar utilidades de sus inversiones, sino de proteger sus ganancias. Por tanto, "invierten" sus fondos en actividades que no necesariamente tienes beneficios económicos para el país donde están los fondos. En algunos países, por ejemplo, se llega a financiar industrias completas sin existir demanda real del bien o servicio, importando únicamente el interés a corto plazo de los dueños del dinero lavado (Bauché, 2006, p. 34).

- Riesgos para los esfuerzos de privatización.

El poder que manejan las personas dedicadas a este tipo de actividades llegan a amenazar los esfuerzos del Estado para introducir reformas en sus economías mediante la privatización. Desde el punto de vista económico, las organizaciones delictivas tienen los medios económicos para hacer una oferta mejor que los legítimos compradores de empresas de propiedad del Estado. Aunque las iniciativas de privatización son económicamente beneficiosas, también pueden servir de vehículo al lavado de fondos y por tanto, también se deben vigilar constantemente este tipo de actividades. En algunos casos los delincuentes del lavado compran lugares de verano, casinos y hasta bancos sólo con el fin de poder ocultar sus ganancias ilícitas y favorecer sus actividades.

Riesgos para la reputación. Aquellos países con un alto índice de operaciones de lavado de activos, pierden la confianza de los demás actores de los mercados financieros internacionales. En este sentido, el riesgo país incrementa y las inversiones $y$ negociaciones de los países podrían verse frustradas. La confianza en los mercados y la importante función económica que cumple el Sector Financiero se erosiona con el lavado de dinero y demás delitos de esta naturaleza, tales como el lavado de ganancias ilícitas, el fraude financiero generalizado, la especulación bursátil y los desfalcos (Paullier, 2011 , p. 11).

\subsection{Estrategias de prevención}

Para hacer frente a este fenómeno, el Estado ha visto la necesidad de fortalecer la estructura del Sistema Financiero e implementar políticas de integración para crear un Sistema Anti lavado.

Las políticas de ataque que el Estado ha implementado forman parte tanto del Derecho del Sistema Financiero como del Derecho Penal, poniendo especial énfasis en esta última; habiéndose logrado implementar una ley que sancione penalmente a aquellas personas que generan este tipo de actividades.

Desde la óptica del Derecho del Sistema Financiero, se ha creado el Sistema Anti Lavado y Contra el Financiamiento del Terrorismo en el Perú - SILAFIT (Decreto Supremo Nº 0018-2006), un Sistema integrado de lucha local e internacional contra el lavado de activos y el financiamiento del terrorismo. Localmente, el SILAFIT está compuesto por los Sujetos Obligados a Informar sobre las operaciones financieras sospechosas, el Ministerio Público, el Poder Judicial, la Unidad de Inteligencia Financiera-Perú, los Órganos Supervisores, los Órganos de Control y la Policía Nacional del Perú, así como por todas las demás instituciones públicas; internacionalmente, forman parte de este Sistema cualquier agencia competente para detectar o denunciar los delitos de lavado de activos y financiamiento del terrorismo (SBS, 2017).

En esta estructura sistémica, tiene un rol especial la Unidad de Inteligencia Financiera, incorporada recientemente a la estructura de la SBS como 
Superintendencia Adjunta, con autonomía funcional y técnica. Su principal función es recibir, analizar y tratar los Reportes de Operaciones Sospechosas (ROS) enviados únicamente por los Oficiales de Cumplimiento de los Sujetos Obligados; así como emitir Informes de Inteligencia Financiera de carácter reservado al Ministerio Público, en caso se presuma que las operaciones están vinculadas a actividades de Lavado de Activos.

La creación de este ente y su vinculación con el regulador del Sistema Financiero, la SBS, una vez más, responde al compromiso del Estado Peruano de luchar frontalmente contra la corrupción, narcotráfico, terrorismo, y narcoterrorismo, considerados temas del más alto interés nacional e internacional.

Así también, durante los últimos meses, se han implementado diversas estrategias para hacer frente a esta guerra financiera. Por ejemplo la aprobación del Plan Nacional de Lucha contra el Lavado de Activos y el Financiamiento del Terrorismo8, el cual materializa el trabajo realizado por diversas instituciones, tanto del sector público como del sector privado. Adicional a la aprobación de este documento se crea una Comisión Ejecutiva Multisectorial encargada de coadyuvar en la coordinación y planificación de las acciones que combaten este tipo de delitos.

Otro de los mecanismos efectuados es la publicación del Modelo de Manual para la Prevención del Lavado de Activos y del Financiamiento del Terrorismo, para aquellos sujetos obligados a informar sobre el detalle de las operaciones sospechosas que se realicen, pero que carecen de organismo supervisor en materia de Prevención del Lavado de Activos y del Financiamiento del Terrorismo9.

La implementación de estas estrategias es una muestra de la preocupación estatal del gobierno para promover y fortalecer los mecanismos de participación de diversos sectores de la sociedad. Sin embargo, diferentes sucesos de la misma naturaleza se siguen presentando. De acuerdo a las estadísticas presentadas por la Unidad de
Inteligencia Financiera del Perú el mayor número de Reportes de Operaciones Sospechosas recibidos según su Ubicación Geográfica entre el 2003-201 1, luego de la Región Lima, fue realizado por las regiones de La Libertad y Lambayeque. Entre los ilícitos que generaron estos reportes se encuentran el Tráfico llícito de Drogas, estafa/fraude, defraudación Tributaria, corrupción de funcionarios, tráfico llícito de armas, defraudación de Rentas de Aduanas, Contrabando, delitos contra los Derechos Intelectuales, proxenetismo, terrorismo (Financiamiento del Tráfico de Migrantes Trata de Personas (SBS, 2011).

\section{CONSECUENCIAS ECONÓMICAS $Y$ POLÍTICAS DEL LAVADO DE DINERO EN EL PERU}

Las consecuencias de este ilícito son varias y de diversa índole, entre las más comunes tenemos la corrupción de las instituciones públicas y privadas, violencia entre los partícipes para mantener el poder logrado, reducción de las actividades productivas lícitas, eliminación de empresas lícitas del sector privado legal, riesgo de desestabilización de las economías legales, sistemas políticos democráticos en riesgo, desigualdades sociales, desconfianza en los sectores financieros, formación de burbujas inflacionarias, entre otros (Vegas, 2007).

\section{PREVENCIÓN DE LAVADO DE ACTIVOS EN EL PERÚ}

Para hacer frente a la problemática generada por el fenómeno del lavado de activos, diversas legislaciones han decidido fortalecer sus sistemas, optando por enfrentar esta actividad desde diferentes perspectivas. Desde la óptica exclusivamente penal los Estados han enfatizado un papel preventivo-represivo, dentro del cual el rol de las instituciones del sistema financiero resulta de gran utilidad.

En tal sentido, se requiere de una activa colaboración de los agentes financieros, quienes puedan tener la capacidad de constituirse en el 
primer filtro para la lucha contra el delito, alertando a las autoridades sobre posibles casos de lavado de dinero. De esta manera, el control preventivo de las operaciones sospechosas queda en manos de los funcionarios y demás empleados de los bancos, quienes tendrían la obligación de observar cómo se manejan las operaciones de sus clientes, estando alertas sobre la presencia de indicios de posibles hechos delictivos para los fines pertinentes (Frisancho, 2006). Sin embargo la estrategia es del todo relativa.

Dentro de los cambios más representativos que se presentan en el Perú desde la última evaluación, es dable remarcar la promulgación de la Ley N 29038 mediante la cual se incorpora la Unidad de Inteligencia Financiera del Perú a la Superintendencia de Banca y Seguros como una unidad especializada, otorgándole a su máxima autoridad el rango de Superintendente Adjunto.

Por otro lado, cabe mencionar algunas disposiciones que se han realizado en la medida de fortalecer las facultades del Oficial de Cumplimiento cuya función principal es la de reportar las operaciones que puedan ser inusuales y aquellas que terminen siendo sospechosas. En este sentido todas las personas naturales $y$ jurídicas que son sujetos obligados a informar a la UIF-Perú definido en la Ley $N^{\circ} 27693$ deben designar a un Oficial de Cumplimiento. Las empresas bajo la supervisión de la SBS tienen la obligación de solicitar a estos clientes una declaración jurada en la cual indique que tiene Oficial de Cumplimiento registrado ante la Superintendencia. El Oficial de Cumplimiento podrá ser el propio sujeto obligado cuando éste sea persona natural, para los casos que la normativa lo permita.

\section{CONCLUSIONES}

Luego del análisis del proceso de lavado de activos y las implicancias económico financieras que este fenómeno acarrea, se ha podido llegar a las siguientes conclusiones:

1. El lavado de activos es el proceso mediante el cual se busca ocultar el origen ilícito de algunos bienes y aprovechar las ganancias provenientes de actividades delictivas, para convertirlos en otros que aparentan ser lícitos y en definitiva no lo son.

2. Frente al delito de lavado de activos, las entidades financieras tienen mecanismos de alerta que sirven para la detección y comunicación de transacciones sospechosas para detectar cuando se está movilizando capitales de origen ilegal.

3. Es necesario que el personal de las entidades financieras esté atento a las señales de alerta que podrían brindar los clientes. Por ejemplo, que la actividad que realiza no sea congruente con sus negocios habituales; que se aprecien características inusuales en las actividades realizadas, intentos exagerados por incumplir con los requisitos de información o diligenciamiento de formatos para actividades de transferencias de fondos, otorgamiento de información insuficiente y que además podría ser sospechosa, entre otros.

4. Resulta inútil protegerse bajo la figura del secreto bancario, para omitir la entrega de información a quien corresponda. En tal sentido, el personal que labora en las entidades bancarias debe comunicar al órgano competente de las operaciones sospechosas de lavado de dinero, sin necesidad que esto implique incurrir en la violación del secreto bancario. El fundamento de esta afirmación reposa en el hecho que ningún derecho es absoluto, sino que tiene sus límites. Así, el derecho a gozar de la protección del secreto bancario es limitado cuando existe evidencia que algún cliente está manejando o transfiriendo dinero ilícito.

5. La Unidad de Inteligencia Financiera del Perú (UIF) es la encargada de transmitir información para la detección del Lavado de Activos y/o Financiamiento del Terrorismo; así como, coadyuvar a la implementación los Sujetos Obligados de sistemas de prevención para detectar operaciones sospechosas.

6. Es justo, y de imperiosa necesidad que el Estado siga implementando mecanismos para 
fortalecer el Sistema Anti lavado que se creó hace algunas décadas; todo ello a fin de hacer frente a este fenómeno que cada vez se está haciendo más fuerte. De esta manera se deben crear políticas públicas eficientes para prevención de crimen organizado transversales.

\section{BIBLIOGRAFÍA}

Bermán, E. (2006). Lavado de dinero, encubrimiento y lavado de activos. Buenos Aires, Argentina: Ediciones Jurídicas.

Cano, M. (2001). Modalidades de Lavado de Dinero y activos. La responsabilidad de la gerencia frente al lavado de dinero, Bogotá, Colombia: ECOE Ediciones.

De la Cuesta, J. (1999). Características de la Actual Política Criminal Española. Cuadernos de Derecho Judicial. Política Criminal Comparada, Hoy y Mañana, Madrid, España: CGPJ

Falconí, M. (2010). Sistema Bancario en la legislación y jurisprudencia peruana. Arequipa, Lima: Editorial ADRUS S.R.L.

Figueroa, H. (2010). Derecho del Mercado Financiero. Lima, Perú: Editorial Grijley.

Frisancho, M. (2006). Tráfico de Drogas y Lavado de Activos. Lima, Perú: Jurista Editores.

Gálvez, T. (2004). El Delito de Lavado de Activos. Lima, Perú: Editora Jurídica Grijley.

Grupo de Acción Financiera de Sudamérica (GAFISUD) (2008). Informe de Evaluación Mutua Anti Lavado de Activos y contra el Financiamiento del Terrorismo (3ra Ronda).

Lester, J. (2001). Aplicación de las leyes sobre lavado de dinero: el rastreo del dinero. Periódico Perspectivas Económicas Periódico Electrónico del Departamento de
Estado de Estados Unidos, Volumen 6, (2), $12-17$

McDowell, J. (2001). Las consecuencias del lavado de dinero y el delito financiero. Periódico Perspectivas Económicas - Periódico Electrónico del Departamento de Estado de Estados Unidos, Volumen 6, (2).

Prado, V. (2007). Lavado de Activos y Financiamiento del terrorismo. Lima, Perú: Editorial Grijley.

Sánchez, L. (2002). Luis. Lavado de Dinero, delito trasnacional. Buenos Aires, Argentina: La Ley.

Superintendencia de Banca y Seguros - SBS (2001). Prevención de lavado de Activos y Financiamiento del Terrorismo - Módulo I Unidad de Inteligencia Financiera del Perú y Lavado de Activos. Lima, Perú: SBS.

Paullier, V. (2001). Manual de Prevención del Lavado de Activos y Financiamiento del Terrorismo, Versión 9.

Prado, V. (2007). Lavado de Activos y Financiamiento del terrorismo. Lima, Perú: Editorial Grijley.

Prado. V. (1998). El Tráfico de Drogas en el Perú. Enfoque Político Social. Cultural. Lima, Perú: Editorial Cuzco.

Superintendencia Adjunto - unidad de Inteligencia Financiera del Perú (2011). Estadísticas operativas al 31 de Agosto del 2011. Recuperado de http://www.sbs.gob.pe

Rubio, M. (1998). Legislación Peruana sobre Drogas a partir de 1920. Lima, Perú: Editorial CEDRO.

Tam, F. (2011). Plan Nacional de lucha contra el Lavado de Activos y el Financiamiento del 
Terrorismo. Lima, Perú: Editorial de la Superintendencia de Banca, Seguros y Administradoras de Fondos de Pensiones.
Vegas, A. (2007). El fenómeno del Lavado de Activos en el Perú y su implicancia en la actividad económica mundial y nacional. Revista Jus Empresarial, Volumen 1. 